\title{
Os encantamentos de Michelet, ou o sortilégio da narrativa*
}

\section{Moacyr Laterza Filho***}

RESUMO: Neste ensaio, faz-se uma abordagem de A Feiticeira, obra do historiador francês Jules Michelet, mostrandose os elementos tipicamente ficcionais que the constituem a narrativa. Procura-se posicionar, portanto, o texto de Michelet numa região limítrofe entre os textos ditos "literários" e os ditos "não literários".

Para minha mãe e minhas irmãs para Maria Rita, Tereza e Lúcia feiticeiras a seu modo.

"Ah! Réponds à ma tendresse

Verse-moi, verse-moi l'ivresse".

(da ópera Sansão e Dalila)

* Recebido para publicação em maio de 1996.

**: Mestrando em Teoria da Literatura pela Faculdade de Letras da UFMG. 


\section{INDEX RETROFLEXO}

Jules Michelet escreveu A Feiticeira de janeiro a julho de 1862 e nesse mesmo ano foi feita a sua primeira edição. Poucos meses antes, Victor Hugo publicava Os miseráveis e um ano depois Baudelaire lançava As Flores do Mal.

É com assombro e não sem alguma angústia que a França vê surgir, no seio de sua intelectualidade, uma tal preocupação com a representação simbólica do seu "espaço marginal". Charles Alexandre, discípulo de Michelet, confessa, mesmo, numa carta a Alfred Dumesnil sua decepção ante a deplorável decadência de seus mestres ${ }^{3}$.

A primeira repercussão de $A$ Feiticeira foi de escândalo, tanto pela sua temática, quanto pela própria narrativa, comparada, na época, à de um "mau romance". A França de então não tinha a mais leve idéia do caminho que o discurso historiográfico tomaria menos de cem anos depois...

Posta de lado por algum tempo em favor de trabalhos mais "canônicos" do mesmo autor (como, por exemplo, a História da França ou, ainda, a História da Revolução Francesa, nas quais, diga-se de passagem, A Feiticeira já é "ensaiada"), a obra volta à tona, hoje em dia, justamente por causa das características que causaram o seu esquecimento temporário.

A constituição "anfíbia" da sua narrativa, marcada por uma descoloração cheia de cromatismos sutis, coloca-a na região mais perigosa de uma fronteira já tênue entre os textos ditos literários e não-literários.

Peter Burke, escritor e teórico da História Nova, mostra o quão próximos estão os textos da História e da literatura justamente por aquilo que têm em comum: o discurso. Discurso é construção, representação simbólica ${ }^{4}$.

Assim, é mais do que provável que os escritores dessa corrente particular da História devam muito a Michelet e ao seu estilo, desde o fascínio pela Idade Média, até principalmente à preocupação com a reconstrução do imaginário popular. Reconstrução que desvela seu caráter de versão, traindo o sujeito que a realiza. É por isso, certamente, que Barthes coloca Michelet no plano da. escritura $^{5}$.

\footnotetext{
3 Cf. MICHELET, 1966. p. 19-20.

4 Cf. BURKE, 1992 p. 327-48. O título original desta obra, organizada por Burke e para a qual ele colabora com dois textos, é New perspectives on Historical Writing. O título da tradução brasileira conserva uma curiosa homonínia com a conhecida obra de De Certeau. Tāo mais curiosa, quando se nota que os assuntos que ambas abordam sāo tratados de forma semelhante.

5 Cf. BARTHES, 1988. p. 210-25.
} 


\section{A BRUXA MULTIFORME, OU AS FADAS AMORFAS}

A estruturação formal de A Feiticeira é claramente definível tanto pela abordagem temática quanto, principalmente, pelos "registros narrativos" tomados pelo narrador: Introdução, Livro Primeiro, Livro Segundo e Epílogo. Destes quatro "componentes formais", o primeiro e o último respondem-se, um ao outro, em consonância. Os dois intermediários, bem maiores em tamanho e nos quais encontra-se essencialmente o "corpus" do texto, distinguiemse, um do outro, pela nítida diferença entre as suas configurações narrativas e, dentro delas, entre as posturas do narrador e as maneiras em que ele constrói, em um e em outro, a personagem principal.

A narrativa do Livro Primeiro encontra-se repleta de mudanças drásticas de "registros narrativos", recurso que, de uma certa forma, fragmenta a linha cronológica e seqüencial do texto, promovendo a reversão daquilo que Alfredo Bosi chama de "visão sintática do tempo" e que serve a uma concepção específica de História ("sequiência, também", mas que não se propõe a tratar o tempo em uma "linguagem de irreversibilidade")". Por isso mesmo, esse recurso mostra-se fundamental para a constituição da personagem. Por um lado, o narrador quer-se menos registrador factual do que entendedor das contradições da alma humana:

"(...) descrevi as situações, os sentimentos, os progressos no desespero que podem levar ao terrivel pacto e ao que é bem mais simples do que o pacto: o horrivel estado de feiticeira".?

Curiosa postura para um historiador. No entanto, não seria este o grande anseio dos poetas contemporâneos de Michelet?

Por outro lado, esse mesmo recurso funciona como um artifício narrativo que ajuda a configurar a aparência plástica e fluida da personagem principal. $O$ narrador, a partir deste artifício, consegue não só fazer com que a sua protagonista percorra trezentos anos de existência dentro da narrativa, como também logra conferir-lhe diferentes "faces", em resposta às diferentes posturas que ele assume: ora narra em terceira pessoa, ora afirma-se bruscamente em primeira, através, por exemplo, de notas de pé-de-página. Por vezes, mostra-se cientificamente frio, citando textos e fontes; por outras, tece digressões com uma iro-

6 Cf. ABENSOUR, 1994. p.20. 7 MICHELET, s/d. p. 45, As citaçōes dessa mesma obra serĩo indicadas apenas pelos números das páginas
em que se encontran. 
nia mordaz, procurando justificar, a cada instante, as atitudes da protagonista.

Paul Viallaneix, que prefacia a edição francesa de 1966 de A Feiticeira, tem uma opinião bem particular sobre isso:

"Il (Michelet) prétend se conduire en historien, non en romancier, quand il raconte 'la vie d'une même fenme pendent trois cents ans' (...). Qui est la Sorcière, en effet? (...) Elle est un type féminin. Elle ne se confond avec aucun des individus qui le répresentent successivement. Elle appartient à son sexe. Elle dépend, plus encore, de la société qui l'envestit de sa fonction. Si l'Eternel Féminin l'habite, l'histoire, une certaine ère de l'histoire occidentale la justifie. C'est pourquoi son historien lui prête, a bon droit, une destinée impersonelle et plusieurs siècles de vie"."

Sem negar a consistência da argumentação de Viallaneix, é preciso mostrar que, em sua exposição, ele não leva em conta a própria narrativa. Se a feiticeira é um "tipo feminino", ela é também, e sobretudo, elemento constituinte do tex to e constituída pelo texto, fio mesclado indispensável para a formação de uma trama bem particular. No texto, pela sua relação com o narrador, entre tantas outras razões, ela é personagem.

É por isso que o próprio narrador the confere uma aparência tão mutável e tanto tempo de existência. Ele precisa "dar conta das nuanças por que ela passa, de sua complexidade, das lutas interiores e de seus conflitos". Precisa "explicar como essa alma, gradualmente, pôde tornar-se viciosa" (p. 11). Para tanto, lança mão de diversos "registros" narrativos que ele mesmo configura.

Em fluidez inquieta, o narrador dificulta propositalmente o reconhecimento da sua postura, da forma como atua e do lugar em que se encontra. Assim, torna-se indefinível o momento em que um "registro" se transforma em outro. O narrador, da mesma forma que suas personagens, move-se plástica e incessantemente, adquirindo, a cada instante, feições diferentes:

"Sentada à sua porta, a dama deste palácio tece, enquanto vigia algumas cabras. Näo se é ainda rico o bastante para possuir uma vaca, mas se Deus abençoar a casa isso ainda acontecerá. A floresta, algum alimento, abethas nos bosques, eis a vida". (p.35).

O Livro Segundo comporta uma estrutura narrativa bastante diferente, à parte de um trecho de transição que abarca os seus cinco primeiros capítulos.

8 MICHELET, 1966. p. 20. 
Esse trecho, ainda bem permeado pelos recursos narrativos do livro anterior, já anuncia o que estará por vir nos capítulos de seis a doze. O narrador em terceira pessoa impõe-se insistentemente, até que adquire relevância majoritária na narrativa dos processos das "possuídas" do século XVIII, em especial, o das possuídas de Loudun e o de Cadière.

Apesar de ainda serem ouvidas, vez por outra, as vozes das personagens, outros são, aqui, os recursos narrativos utilizados.

O narrador em terceira pessoa, onisciente, na maior parte do tempo (ao aproximar-se do Século das Luzes, Michelet usa a máscara da razão...), constrói uma narrativa que se assemelha bem de perto, agora sim, à do romance tradicional, seja na postura do narrador, seja na concatenação temporal dos fatos, seja na configuração das personagens. Michelet usa, para isso, de recursos bastante típicos da estruturação de novelas, à maneira de Balzac:

"(...) O que é certo é que a criança, entre duas crenças, cheia de agitações e de medo, tornou-se a partir de entäo vítima de acessos de loucura que às vezes conduziam à epilepsia. Tinha medo de ser carregada viva pelo Diabo. Ela não conseguiu mais ficar na casa do padre e fugiu para o convento das ursulinas de Marselha.

Capítulo seis

(GAUFFRIDI - 1610)

De todas as ordens religiosas, a das ursulinas parecia a mais calma e a menos incoerente (...). (pp. 140-141).

Tal é a transição feita para o capítulo em que o narrador em terceira pessoa afirma-se decisivamente.

Além de tudo isso, deve-se notar que os próprios títulos dos capítulos, se não refletem, endossam a estruturação formal e os procedimentos narrativos do Livro Primeiro e do Livro Segundo. "Encantos, filtros", "O pequeno demônio do lar", "O rei dos mortos", "A posse": tais são alguns dos títulos do Livro Primeiro. Se eles sugerem uma determinada maneira de narrar, esta é bem diferente daquela sugerida por "O processo de Cadière - 1730-1731", último capítulo do Livro Segundo... 


\section{MANES, LARES E PENATES}

"Deve-se dizer 'a heresia das feiticeiras' e não 'dos feiticeiros'; estes têm pouca importância". (p.07).

Citando Sprenger, Michelet, já nas primeiras linhas da introdução instaura a mulher e, mais do que isso, a feiticeira, como personagem central da narrativa. A mulher feiticeira é posta como centro temático de toda a obra e, através dela, ele tenta desvelar uma única "alma", que se apresenta ora sob uma determinada "maquiagem", ora sob outra. Pode-se notá-lo, por exemplo, no caso da feiticeira construída no Livro Primeiro, com sua pureza e sua visceral ligação com a natureza (que Michelet grafa insistentemente com letra maiúscula), em oposição às "possuídas" dos processos relatados no fim da obra, sua conduta histérica e a maneira como são manipuladas pelas autoridades seculares e eclesiásticas.

No texto, parte-se da mulher para se chegar à feiticeira. Esta oposição (bem como aquela entre as feiticeiras dos livros Primeiro e Segundo) funciona como um recurso que permite configurar com mais expressividade as contradições inerentes à própria personagem, em suas várias faces.

Na natureza da mulher (mesmo daquela ainda não pactuada com o diabo) já se encontram os elementos fundamentais da magia:

“' a natureza as fez feiticeiras'. - É o gênio próprio à mulher e seu temperamento. Ela nasceu fada. Pela volta regular da exaltação, ela é Sibila. Pelo amor, ela é Mágica. Por sua fineza, sua malícia (muitas vezes fantástica e benfazeja) ela é Feiticeira, e faz, sorte, ou, pelo menos, adormece, engana os males". (p.07).

Ela, como é mostrada aqui, já é feiticeira. Não em toda plenitude dessa palavra, mas em potencial, pois ainda não há o pacto diabólico, nem os sabás, nem tampouco ela é a representação simbólica da resistência popular às imposições da igreja. Tal é o "ponto de partida" que o narrador toma para chegar à verdadeira feiticeira, guardiã do paganismo e criadora da medicina e, assim, instituída no texto como personagem, ser ficcional elaborado pela voz do narrador, ele próprio também ser ficcional, que lhe dá, segundo uma ou outra conveniência, aparências diferentes, mostrando-nos, dela, faces diferentes.

"A Natureza enterrada retorna, não mais furtivamente, mas agora na qualidade de dona da casa". (p. 25). 
A família é o palco do surgimento da mulher. Aí ela "nasce", ao mesmo tempo como metáfora da natureza e sua guardiã e é aí que ela se afirma em seu papel social.

Foco pagão dentro do Cristianismo, força de resistência popular ao idealismo monástico, que vence com glória, a família é "restabelecida" pelo "desmembramento do lar coletivo". Dessa vitória e dessa resistência, a mulher é símbolo e força. Ela é guardiã de um "misterioso e fascinante mundo habitado por fadas, duendes; propício à alma feminina" (p. 36). Seu espaço social confere-lhe a árdua tarefa de manter viva a tradição popular - transmitida de mãe para filha - e nisso a mulher se constitui:

"A verdadeira família nasceu com o desmembramento do lar coletivo. Ao construir seu ninho, o pássaro estava construindo a si mesmo. A partir de então, eles não eram mais simples objetos, mas almas... A multher nascera". (p. 35).

Ela é guardiã da lenda, da autenticidade pagã sufocada pelo cristianismo. Protege os espíritos do lar e dos bosques (agora não mais "Manes" ou "Lares", mas duendes e fadas), é "alma encantada" "que se ocupa também em salvar toda a natureza e toda a sociedade", é força da resistência pagã e da reação popular. Nisso se encontra o germe fundamental da feiticeira.

Ao mostrar, na narrativa, a constituição da mulher a partir do "renascimento" da família, Michelet reforça, também, seu caráter de personagem. $O$ espaço em que ela se insere dentro do texto, as metonímias que a representam, o leve murmúrio inicial de sua voz (que transformar-sé-á paulatinamente nos urros histéricos das "possuídas" do século XVIII) marcam com mais ênfase, nesse momento do texto, o tratamento ficcional dado por Michelet à mulher feiticeira:

"Ela agora possui alguma coisa. E se interessa por ela. A roca, a cama, a arca. É o que diz, a velha canção, à mesa se junta um banco, ou duas toscas banquetas... pobres móveis! Mas a casa tem uma alma por mobília. O fogo a torna mais agradável, o ramo bento protege o leito, onde, às vezes, 'é também colocado um buquê de margaridas". (p. 35).

De mulher a feiticeira, a transformação se dá, no texto e com o texto, em dois níveis. O primeiro, individual, apenas traz à tona uma predisposição latente no espírito feminino. A mulher é ser demoníaco. Ela é, "sobretudo, habitada por esses tiranos, que a revestem de uma aura infernal, atormentam seu coração, conduzindo-a ao pecado, ao desespero" (p. 22). O segundo, social, é o que 
provoca os "tempos de desespero". Neles, "o homem sentia a ausência de Deus. Cada devastação demonstrava que este reino era de Satanás, que era a ele que se deveria recorrer" (p. 44).

Entretanto, a diferenciação narrativa estabelecida entre Livro Primeiro e Livro segundo evidencia o tratamento dado à configuração da "mesma alma" a que Michelet se refere: de um lado, a afetividade e a delicadeza da mulher original, feiticeira latente, fada, sibila. De outro lado, a histeria gerada pela imposição à mulher de um papel e de um lugar sociais por uma sociedade masculina que tem seus modelos nos hábitos eclesiásticos. Isso explicita, talvez, dois lados paradoxais da mulher. Daí a fluidez com que o narrador se move para poder pintar a sua personagem.

É a mulher, por sua predisposição natural ao diabólico e por sua particular relação com a Natureza (ela destrincha os animais, observa o tempo e os homens), é ela que surge como alento em épocas "de atrozes necessidades". Imola-se, através do pacto, a Satã, num gesto que depois será ritualizado nos sabás.

Pela tentação dos espíritos domésticos que protege e pela pressão de épocas em que "o próprio inferno se assemelha a um asilo, em relação ao inferno daqui de baixo" (p. 49), a mulher é tomada, ela mesma, de desespero e tem, com trágica consciência, a sua vontade vencida. Assim consuma-se o pacto.

Possuída, ela tem un "penetrante olhar de Medéia", usa um vestido verde, cor do "Príncipe do Mundo", metáfora da natureza. Poderosa, ela vence. Pela vitória, é marginalizada. Retira-se, rechaçada, para a floresta ou para o pântano, onde Satã abre-lhe o caminho do conhecimento:

"A natureza estava transformada. As árvores tinham língua, relatavam fatos passados. As plantas eram medicinais; as mesmas plantas que ontem ela pisava com desprezo eran agora pessoas que falavam de medicina". (p. 61).

A mulher transforma-se socialmente em feiticeira. Germina, nela, a semente da ciência. 


\section{UM PARADOXO}

Jean Delumeau, na História do medo no Ocidente, confirma e comprova "historiograficamente", se não na íntegra, boa parte do texto de Michelet. Situa-o, inclusive, dentro de uma das correntes ideológicas que "seduziram os pesquisadores" no propósito de "resolver esse grande enigma histórico": a dos comportamentos populares.

Delumeau, no entanto, entra em um certo desacordo com essa corrente. Ele não contesta explicitamente o procedimento narrativo, propriamente dito, de Michelet, mas as fontes que o proporcionaram. Além disso, insiste em que os autores dessa corrente, referindo-se logicamente aos sabás, "não explicam como nem por que organizaçōes rituais, que permaneceram subterrâneas durante mil anos, reapareceram em seguida".

Ora, pois é justamente isso o que faz Michelet através dos recursos ficcionais que usa em sua narrativa. A mesma "alma" que percorre trezentos anos, em seu texto, guarda, nas tradições, como já se procurou mostrar, esses ritos ancestrais.

Por outro lado, é certo que a documentação usada por Michelet não era exatamente "partidária" das figuras sociais que ele traz à luz. Seria ingênuo, ainda, pensar que se produzisse um tal texto, como o seu, através da pura negação das argumentações apresentadas nos relatos de processos e nas obras dos demonólogos dos séculos XVI e XVII.

Como, então, explicar o apaixonado posicionamento de Michelet ao lado dos "excluídos sociais", tendo em vista essa incoerência documental? A propósito disso, é mister lembrar a reversão que faz Jacques Le Goff́ do conceito de documento:

"(...) resulta de um esforço das sociedades históricas para impor ao futuro - voluntaria ou involuntariamente - determinada imagem de si próprias. No limite, não existe um documento-verdade. Todo o documento é mentira"."

Michelet busca, em seu texto, essa mesma "imagem" tomando o caminho inverso: questionando-a, ou, antes, apontando a sua fragilidade através de seu oposto. Não se trata puramente de negar as suas fontes, mas, antes, de ter lúcida consciência de que "o documento é um produto da sociedade que o fabricou

9 Le Goff, 1994. p. 548.

CALIGRAMA - Belo Horizonte, 2:131-141 - novembro/1997 
segundo as relações de força que aí detinham o poder". E ainda de que "só a análise do documento enquanto monumento permite à memória coletiva recuperá-lo e ao historiador usá-lo cientificamente, isto é, com pleno conhecimento de causa" 10 .

Reconstituindo o imaginário popular de uma determinada sociedade em sua fluidez de transformações durante trezentos anos, Michelet promove essa recuperação usando recursos que não são propriamente específicos do discurso historiográfico.

Por outro lado, é justamente por isso que sua empresa é bem sucedida. Posicionando-se voluntariamente nesse limiar entre a objetividade e a sedução, seu discurso é, ao mesmo tempo, poesia e ciência, narrativa feiticeira.

RÉSUMÉ: Dans cet essai, on fait une approche littéraire de La Sorcière, oeuvre de l'historien français Jules Michelet, en indicant ce qui appartient proprement à la fiction dans son texte. C'est notre intention le placer à la frontière des textes qứ'on appelle littéraires et ceux qui ne sont pas mis dans cette classification.

\section{REFERTENCIAS BIBLIOGRÁFICAS}

ABENSOUR, Miguel et alii. Tempo e História. Organização de Adauto Novaes. São Paulo: Companhia das Letras, 1994.

BARTHES, Roland. O Rumor da lingua. Tradução de Mário Laranjeira. São Paulo: Brasiliense, 1988.

BOSI, Ecléa. Memória e sociedade. São Paulo: EDUSP, 1987.

BRANDÃO, Carlos Rodrigues. "Papéis, personagens e pessoas." In: Identidade e etnia. São Paulo: Brasiliense, 1986.

BURKE, Peter (org.). A escrita da História. Novas perspectivas. Tradução de Magda Lopes. São Paulo: EDUSP, 1992.

CERTEAU, Michel de. A escrita da história. Rio de Janeiro: Forense-Universitária, 1982. DELUMEAU, Jean. História do medo no ocidente: uma cidade sitiada, 1300-1800. Tradução de Maria Lúcia Machado.Tradução das notas de Heloísa Jahn. São Paulo: Companhia das Letras, 1993.

10 Le Goff, op. cit, p. 545 . 
DUBY, Georges. Idade média, idade dos homens: do amor e outros ensaios. Tradução de Jônatas Batista Neto. São Paulo: Companhia das Letras, 1989.

Laterza, 1991. e PERROT, Michelle (org.). Storia delle donne: Il medioevo. Bari:

LE GOFF, Jacques et alii. A nova história. Tradução de Ana Maria Besssa. Lisboa: Ediçōes 70, s/d. História e menória. Campinas: UNICAMP, 1994. (org.). O homem medieval. Lisboa: Editorial Presença, 1989.

MICHELET, Jules. A feiticeira. Tradução de Ronald Werneck.. São Paulo: Círculo do Livro, s/d. - La sorciere. Paris: Garnier-Flammarion, 1966.

. The people. Versão inglesa de John P. McKay. Urbana/Chicago/ London: University of Illinois Press, 1973.

RICOEUR, Paul et alii. Grécia e mito. Tradução de Leonor Rocha Vieira. Lisboa: Gradiva, 1988.

RIEDEL, Dirce Cortes (org.). História, ficção e narrativa. Rio de Janeiro: Imago, 1989.

SOUZA, Laura de Mello e. A feiticeira na Europa moderna. São Paulo; Ática, 1987. 